\title{
Doing Visual Activism. A Practice-based Approach to the Study of Visual Social Media Use by Kia'i Mauna Kea
}

\author{
Moshe Karabelnik \\ University of Hawai'i at Mānoa \\ moshekar@hawaii.edu
}

\begin{abstract}
This article applies a practice-based approach to the study of social movements using visual social media. The article explores the visual practices of the social activist group Kia'i (protectors) [of] Mauna Kea, a sacred summit on the island of Hawai' $i$ and the proposed location of the world's largest telescope: The Thirty Meter Telescope (TMT). Following Nick Couldry [1], this article poses the question: What do Kia' $i$ do with visual social media? To answer this question, the use of Instagram by Kia' $i$ was examined using the methodology of Visual Cross Platform Analysis [2]. This research expands on VCPA methodology, implementing a practice-based approach to uncover how practices of visual social media anchor [1] and overlap the practices of social movements [3]. This article brings to light some of the complex practices used by social activists to regain control over symbolic capital [4] from state and media institutions.
\end{abstract}

\section{Introduction}

The narrative of Mauna a Wakea as a sacred piko (Navel, also summit) of Hawaiian people[5]-[7]. Often - though not exclusively - begins with "The mele ko'ihonua about Papahānaumoku ('island-birthing stratum'; the earth mother, also known as Papa) and Wākea ('the wide open expanse'; the sky father) [which] relates the origin of the Hawaiian Islands through the union of Papa and Wākea, and through their unions with others"[5]. The importance of this mele (chant or poem), as well as of practices of burying remains of family members under secret shrines on Mauna Kea [8], [9] and stories of deities in female form living on Mauna Kea [5], [9] are a few of the many ways Mauna Kea is sacred to Kanaka Maoli (Native Hawaiians).
For Kia'i, the major obstacle in the struggles to protect Mauna Kea, as well as other sacred places in Hawai'i, is navigating the laws of the state of Hawai'i. Fighting for sacredness in the courts, forces protectors of Mauna Kea into an asymmetrical battlefield against the Bureau of land and natural resources (BLNR) and the State at large. The struggle is best described in the words of Mehana Kihai, a protector of Mauna Kea, in her testimony in the BLNR contested case in 2013: "I am a native Hawaiian, a mother, a breakfast waitress, I have no legal background and no experience in a legal system, and I am standing here, among some of the highest paid lawyers in all of Hawai'i. Why am I here?! Why do I need to be here, to convince you to do your job?" [10]. Kihai's words echo three dimensions of the power differential between Kia'i and the state in this contested case and other legal processes: First, the use of legal apparatus and language requires expertise, financial and emotional resources, and time. Such is the "power differential embodied within the actual space of the struggle, the courts. The petitioners are ordinary people; none of them are lawyers or independently wealthy. They have all made enormous sacrifices by missing work, sleep, and family and other personal obligations to focus on the case. Such work is a full-time commitment. Conversely, the University spares no expense in the legal battle" [9]. Secondly, moving the discussion into courts imposes legal terms that may be ill equipped to address claims of sacredness: "law determines that very specific boundaries be placed on the types of questions that are to be ruled on. By narrowing the terms of discourse as courts necessarily do, only a very limited range of questions comes under scrutiny. The broader questions of reparative justice or the origins of the State's legal authority, for instance, are never open for discussion or subject to debate"[9]. Lastly, discussions are held in courtrooms, which allow only a limited number of stakeholders and interested audience to participate. Anyone else that is interested in the case must view proceedings through the media - television and newspapers - where events are framed by interests of 
media owners and "television coverage (or the lack of it) could potentially make or break a movement"'[11]. Thus, most of the symbolic capital - a term developed by Bourdieu, generally meaning any type of capital (economic, cultural, and so on) that happens to be legitimated or prestigious in a particular field[4] - in the discourse and representation of Mauna Kea is held by media conglomerates and state institutions. Therefore, Kia'i Mauna kea, as do other social movements, document acts of civil disobedience, peaceful protest, gatherings and concerts, clashes with police, court proceedings and other events. To generate their own symbolic capital in the discursive and legal battle for Mauna Kea.

In October 2013, three Kanaka 'Ōiwi (Another term for Native Hawaiians) University of Hawai'i-Mānoa graduate student activists - Haley Kaili'ehu, No'eau Peralto and 'Ilima Long - decided to present a Kanaka vision of Mauna Kea, as part of the annual 'Ka Leo Arts Festival'. The student artists saw the mural as an opportunity to raise awareness about the sacredness of Mauna Kea on the University of Hawai'i-Mānoa campus and to show the petitioners in the contested case - now appellants in the appeals case against BLNR - that Kanaka O`ahu (Hawaiians on O'ahu) were standing with them in solidarity [9]. The mural included a message demanding that the University of Hawai'i, as a Hawaiian place of learning, take responsibility for their desecration of the Mauna and allow Kanaka students opposing discourse. The message was later removed by Ka Leo management, an act which sparked a protest march by students and allies, leading to an apology by Ka Leo, a delay in UH's negotiations to renew its lease on Mauna Kea and most importantly, a re-kindling of the opposition to the construction of the TMT and of discourses of sacredness surrounding Mauna Kea. [9] Culminating a few years later with Mehana Kihai's statement: "They thought they were building a telescope, instead they awoke a nation" [10]. The Mural Exemplified the ways "movements can use art to carry out framing work, mobilize resources, communicate information about themselves, and, finally, [act] as a symbol of the movement" [12]. This use of communal artistic work to communicate messages, support activists and offer a dissenting discourse, has accompanied more traditional resistance technics such as demonstrations, roadblocking's and occupying space as a way for Kanaka Maoli to tell their own mo'olelo.

Mo'olelo - practices of delivering information, telling (his)stories, and conducting societal activities, such as asserting genealogy, asking permission, or negotiating Kapu (a way of marking the sacred). Is always performed in audio-visual protocol in the form of art, chants (mele) and dance (hula). These forms of expression are used by Kanaka to create a native discourse about the sacredness of Mauna Kea which challenges the discourse of western law used in courts. In the words of Jamaica Osorio: "In this way, while we Kanaka continue to live in a society where rights over land, development and progress are so heavily contested, our charge as we continue to speak, dance, and chant the law daily is increasingly dangerous to the maintenance of the settler state $[. .$. When we come to the law as a mo'olelo, or something we must speak, ever evolving with many mana, and with as much mana as we choose to recognize as a collective, we destabilize the assumed pre-eminence of Western law in the settler occupation of Hawai 'i." [7]. Nevertheless, chants, hula, and oral performances of mo'olelo, are inherently limited in their distribution to an audience that is physically present to witness them. Therefore, until recently, Kanaka Maoli wanting to voice their opposition to the state and share it with the kanaka population spread across the Hawaiian Islands, used petitions and letters to voice their own mo'olelo of events. These written forms of protest persisted for decades, from resistance to the bayonet constitution, to the early resistance to astronomy on Mauna Kea in the 70's which "came through letters to the editors of local newspapers, oral and written testimonies at public hearings, [and] letters to the Department of Land and Natural Resources" [9]. Granted, in different times in history these methods were successful [13] temporarily stopping annexation and, almost a century later, leading to the auditing of BLNR [7], [8] and to a contested case against the TMT. Yet, the reliance on newspapers and petitions is afflicted with the same problems as the legal process: Leaving most of the symbolic capital in the hands of the state and the media, forcing petitioners to turn to the English language, and not always reaching kanaka population across the islands. Moreover, when viewing these petitions as mo'olelo, it is important to bear in mind that "Although mo"olelo found a home in the medium of print in the twentieth century, it is ultimately an oral tradition, and the words function as a means to engage all of the senses, not just sight and sound" [14]. While petitions and letters have had some legal success, they were not effective in bringing the resistance to astronomy on Mauna Kea to the attention of Kanaka and allies across. As Salazar notes: From the 1970's until the 2013 mural "for those not living on Hawai'i Island, Mauna Kea was rather out of sight and out of mind "[9]

Therefore, it is important to ask in which ways Kia'i and allies could achieve some control over 
symbolic capital, and how, in some ways they have already done so. Why, during the fall of 2019, from Hilo to Lihue, Kanaka and allies were showing their solidarity with the Kia'i on the Mauna: Hanging Hawaiian kingdom flags on their trucks, performing protocol in front of Bachman hall, the administration building for the University of Hawaii system, three times a day and, while thousands marched on the streets of Waikiki. How has the discourse over the summit of Mauna Kea, that only a few years ago was 'out of mind' for those not living on the island of Hawai'i, become a symbol, a piko of sacredness and representation for Kanaka and allies all over Hawai'i? A clue may be found in the accounts of Marie Alohalani Brown, as she details the relationship between visual media and the actions taken to reclaim the sacredness of Mauna a Wakea: "We have, together with our supporters, held vigils, built ahu (shrines), conducted prayers, and performed hula and chants for the mountain. Participants and observers recorded these actions, disseminated these photos and videos online. Moreover, encounters between supporters of Mauna a Wakea and the representatives of the Department of Land and Natural Resources (DLNR), police, and people affiliated with the TMT have been also photographed and videoed and circulated online. Because of this visual documentation, the topic of Ho'omana Hawai'i [set of beliefs and belief-related practices indigenous to the Hawaiian Islands] has also gained worldwide attention" [5].

To further understand Brown's description of the use of visuals to promote a discourse of sacredness and protection of Mauna Kea, and its relationship to the larger discourse around Mauna Kea. It is important to explain the importance of visual social media practices for social movements. When media is seen as practice, visual media practice becomes seamless and inseparable from all other practices [3] involved in social protest. Kia'i use of visual social media will be explored here in terms that transcend content analysis and media-centrality. Invoking the pivotal research question of Couldry's practice approach to media studies: "What do people do with media"[1], [4]? This research asks What do Kia'i do with visual social media? To answer this question, the visual methodology of Pearce et al.[2] will be used to revel and unpack practices of social movements that are bundled [3] into the practice of using visual social media. Building on Pearce et al.'s methodology, image plotting will be used to exemplify how practice presents itself in the visual vernacular[2] of Kia'i use of Instagram. Using a practice-based lens, in conjunction with visual cross platform analysis [2], will demonstrate how this methodology may support large scale, non-media-centric analysis of social movements use of visual social media. The case presented below exemplifies how activist practices of visual social media contribute to the reclaiming of symbolic capital from the state, back to the hands of kanaka.

\section{Social Movements and Visual Media}

So far, the use of visuals by social movements has not taken a central role in social sciences. Nevertheless, "Encounters with social movements have always been intrinsically tied to the visual sense. Activists articulate visual messages, their activities are represented in photos and video sequences, and they are ultimately rendered visible, or invisible, in the public sphere" [14]. The visibility of social movement is not limited to mediated visibility. As Doerr, Mattoni $\&$ Teune remind us, the mere act of taking to the streets and marching, can be seen as a practice of making a conflict visual [14]. That said, the use of mediated images allows social movements more complex message making, framing, and re-framing of messages and, an impact on the reception of contentious actors by attracting media attention and mainstreaming social movement claims. Visual practices assist in recruiting activists and sympathetic audiences both within and outside social media platforms [15]. Social movement activists use selfmediation to advance their goals in multi-layered ways: To mobilize supporters, coordinate actions, manage public visibility, and record protest events [16]. While some of these actions may be achieved by online textual media, print or radio. Images, with their symbolic appeal, circulate wildly through the combination of camera phones and ubiquitous internet connection. Images are able to rapidly and effectively address the imagined collectiveness of audiences [14], efficiently mobilizing activity or generating solidarity. Moreover, Images are a useful tool in encounters with police forces and other agents of the state. Kari AndénPapadopoulos [17] highlights the usefulness of images in producing incontrovertible public testimony to unjust and disastrous developments around the world: "Camera-witnessing" [17] allows activists to inscribe themselves into the event, marking their being there. Furthermore, Andén-Papadopoulos notes the ways in which camera phones can be used by activists as counter weapons against the surveillance of the state: "namely, to before anything else turn their cameraphones into a personal recording device in order to make their eyewitness experience more evidential."[17]. The gesture of raising the camera to record at the scene of mass protests is an active, selfconscious one. Whereby the photographer displays an 
awareness of themselves as a designated witness. Raising a camera phone conjures up the presence of networked publics[18] - who presumably are taking part in this event in near-real time - and forms a powerful 'meta-message' which asserts that the whole world may indeed be watching these disturbing events almost as they happen [17]. Combined with the always online nature of smart phones, these acts of witnessing are enacted in real time through live broadcast, or in near real time as they are disseminated on social networks. In this way, images produced by social media activists transcend their meaning as evidence and evolve into practices of mediated social resistance that may conjure solidarity, effect the narrative, or mobilize more activists to the area of conflict.

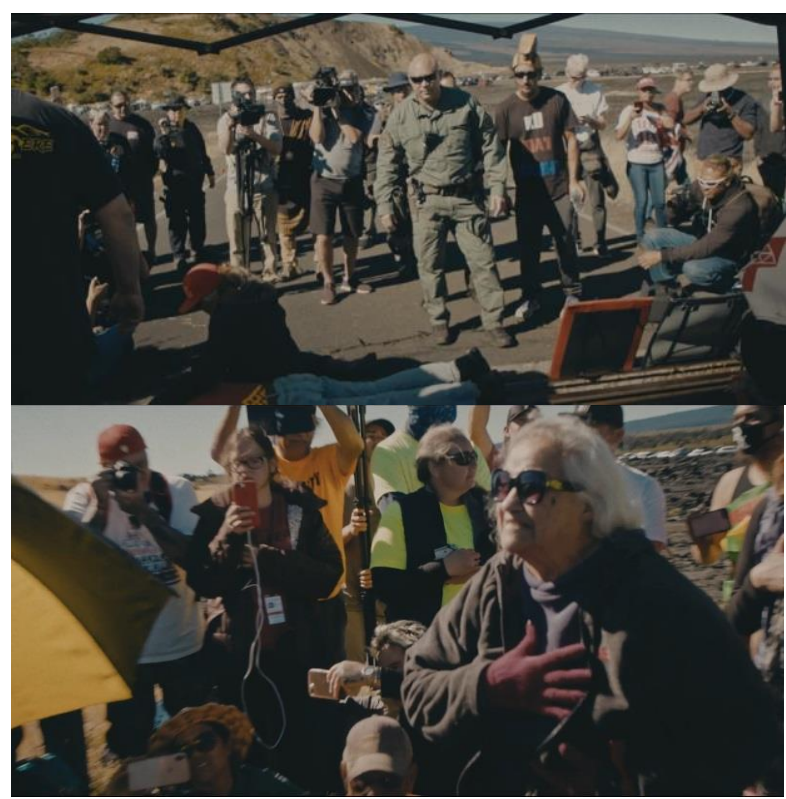

Figure 1. The 'image wars'[17] on Mauna Kea. State and media point cameras at Kia'i (top). Kia'i pointing phone cameras at state officials (bottom)

[19]

Mediated representations of conflict also constitute a part of the image wars [17] over possible futures. As activists find they are not in control of their image as it is produced by journalists, bystanders and police wearing body cameras [14], [20]. It becomes of critical importance for activists to create their own "translation of a private sensory experience into public mediated testimony" [17]. Visual social media is a substantial advantage for activists in the image battlefield, giving social activists utilizing camera witnessing the ability "to become 'a kind of editor, and thus an active shaper of the story of what happened" [21]. Thus, commercial and public mass media no longer have a monopoly over the visual representation of protests [14] as social networking sites such as Twitter, Facebook and YouTube form a 'wild zone of representation' [17] where the affordances of image production and broadcast allow activists to overcome "The intrinsically divisive nature of media's symbolic power, the division of the social between those with access to media's vast concentrations of representational power and those without such access" [3].

\section{The Methodological Challenge of Studying Visual Media}

Martin Hand [15] outlines three basic methodological challenges of researching visuals in social media. "First, [is] the sheer volume of images present in social media platforms" [15] The number of images available online, complicates the process of selecting images for research. Hand claims the number of 'found' images means we must abandon any idea of analyzing individual ones. Therefore, selection bias will always exist in the research and researchers are required to justify their selection process. "Secondly, the production, distribution or 'circulation' of these images through different devices and platforms makes it very difficult to treat them as simply analogous to print images".[15] Print images were largely considered as indexical, physical evidence of real events used for defined social purposes [16]. In contrast, the third challenge of studying social media images is: "[..] the alterable and malleable nature of these images [that] raises difficult questions about establishing the contexts of interpretation, leading to the potential obscuring of the social practices of which the images are part"'[15]. Highfield and Leaver [17] highlight similar methodological challenges to the study of visual social media. They explain that two of the greatest problems in such research are: First, the large quantity of social media visuals, that brings with it questions about their origin and authenticity. And Second, that visual social media is conversational, not archival in nature. As visuals are constantly created and recreated while platform affordances change, it becomes impossible to archive and study images as researchers constantly chase the latest images, making data collection problematic. Pearce et al [2] note how these challenges have created a bias in social media studies towards text-based research, as texts are easier to interpret using big data software. Pearce et al.'s criticism of online social research is similar to Doerr, Mattoni \& Teun's [18], [19] criticism of the focus on texts in social movement research. Moreover, Pearce et 
al recognize how existing visual research is mostly conducted in single platform research. This type of single platform research ignores the fact that online images are 'collapsed objects' that do not carry the same function and meaning across platforms and, how different platform have different affordances for distributing images and allowing visual conversations. Therefore, Pearce et al. offer a visual methodology for the study of the unique visual vernaculars[2] of social media platforms.

\section{Visual Cross Platform Analysis}

To address the methodological challenges of visual social media research, Pearce et al. [2] call for the adoption of visual cross platform analysis (VCPA) to be used in visual social media studies. VCPA involves collecting images surrounding a research subject from multiple social media platforms and comparing them both within the platform, and between platforms. When conducting VCPA, it is important to remain aware of the unique ways in which visual conversations takes place in different platforms. "Notable differences, for example, relate to the prominence of hashtags (tags on Instagram and Tumblr), which are center stage on Twitter but less prominent on Facebook. For Facebook, one might want to consider the role of pages that users like or groups that they join. On Reddit, the 'subreddits' to which users subscribe are essential elements structuring the discourse on the platform" [2]. After data collection, Pearce et al suggest plotting images according to characteristics such as time of posting or color - Pearce et al use the Image Sorter [25] tool to achieve this - according to the principle of 'small multiples' popularized by Tufte [26]. Image plotting allows for easy rapid visual comparison of a large number of images, highlighting patterns in the data [2]. The creation of visuals specifically for visual research is useful for visual analysis just as "Analysis of text generally produces new text, so [..] analysis of images can productively produce new images which can aid identification and interpretation of visual vernaculars" [2]. This research would suggest that Visual Cross Platform Analysis can be used to examine the visual vernacular of Kia'i Mauna Kea. Furthermore, it is the purpose of this research to develop this methodology to implement a practice-based approach and uncover practices of visual social media that anchor [1] and overlap practices of social movement activities [3].

\subsection{Research Participants}

Doerr, Mattoni \& Teune define social movement visuals as visual art, as well as any online visuals, created by a social movements[19]. Following this logic, the visuals used by Kia'i have grown from a mural [9] into an extensive, active and well produced array of social networks employing a "pragmatic attitude towards the combination of diverse media logics that co-exist in contemporary societies" [19]. Thus, on March $7^{\text {th }}, 2014$ almost exactly one year after the events of the Ka Leo art festival. The Instagram account Protect Mauna a Wākea (@ protectmaunakea) [20] uploaded their first image. Followed later by other major Instagram accounts associated with Kia'i [21] such as: Kanaeokana (@kanaeokana) [22] which launched in 2017, as well as Instagram accounts associated specifically with the events of July 2019 on Mauna Kea: Kāko'o Haleakalā (@Kakoo_haleakala) [23] and Pu'uhonua o Pu'uhuluhulu (@puuhuluhulu) [24] both launched that same month. The focus of this article is Instagram, a social network that is primarily visual. Nevertheless, visual media is also shared continually on accounts run by Kia'i and their allies on other social media platforms. Most notable of these visuals, are the live streams of protocol performed three times a day and other events on Mauna Kea. These are published on the Facebook page Kāko'o Haleakalā[25]. While Kāko'o Haleakalā contains high volumes of visual activity compared to other Facebook pages dedicated to Mauna Kea, it should be noted that many pages and Facebook groups not mentioned here highlight the use of visuals as well.

This study focuses on two major Instagram accounts associated with Kia'i Mauna Kea: Protect Mauna a Wākea (@Protectmaunakea) [20] and Pu'uhonua o Pu'uhuluhulu (@Puuhuluhulu) [24]. While Pearce et al. advocate using hashtags as conversation markers in Instagram, this study focuses on images from specific accounts, and not images tagged with a hashtag. This decision arose from preliminary exploration which reveled inconsistent hashtag use by accounts related to Kia'i Mauna Kea. The two accounts were chosen for the following reasons: Protect Mauna a Wākea is the oldest Instagram account out of the accounts surveyed, and thus can serve as a marker for the development of Kia'i's visual vernacular. $\mathrm{Pu}$ 'uhonua o $\mathrm{Pu}$ 'uhuluhulu is connected directly to the network of activists who participated in the events of July 2019. With its accompanying website [26], branding and messaging, it is subjectively the most organized and clear on its message out of the accounts surveyed above. Following the methodology suggested by Pearce et al. [2] I used a Chrome add-on called 'Downloader for Instagram + Direct Message' [27] to download, in bulk, all of the images posted to these Instagram accounts over the time period spanning their creation 
and up to the day of sampling: June $5^{\text {th }} 2020$. In total, 4,119 images were downloaded from both accounts (1452 from $\mathrm{Pu}$ 'uhonua o $\mathrm{Pu}$ 'uhuluhulu and 2667 from Protect Mauna a Wākea). Then, following Pearce et al., Image Sorter [28] software was used to create an image layout of the downloaded images, organized by color. This allowed for an initial exploration of central colors in Kia'i's 'visual vernacular' [2] on Instagram. Color is a good starting point as "Tradition and continuity in social movements is not only produced in narratives and the use of concepts, it is also imagined in elements of graphic design and the use of colors" [18]

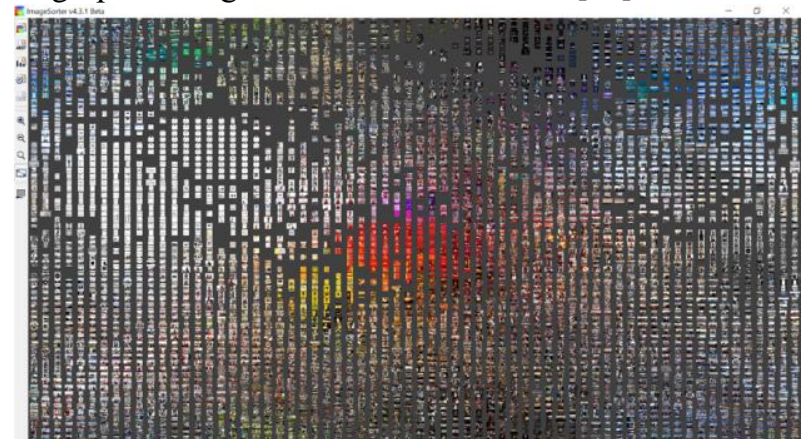

Figure 2.@protectmaunakea and @puuhuluhulu Instagram accounts. image plot sorted by color in Image Sorter [28]. 4119 photos

Immediately, three distinct color blocks become apparent in the image. In the center of the image, are the red and yellow colors of Ali'i (Chiefs) are very prominent. These colors were adopted by Kia'i to symbolize their genealogical connection to historical leaders of Hawai'i. While these colors appear in many images published in these accounts - flags, stickers and apparel worn by activists - They are most prominent visually in posters publicizing events and activities shared on both accounts. These make up the big red spot in the center of the plot. The second distinct block of color is white. Consisting of screenshots containing textual information geared to convey information, elicit solidarity, and mobilize activists. For the most part, Visual vernacular of Instagram is predominantly comprised of aesthetically pleasing images and not textual screenshots [2], [29]. Thus, this textual use of Instagram points to a unique 'visual vernacular [2] employed by Kia'i on Instagram. The third block of distinct color, on the upper right corner, contains bright blue with white patches. These are images of Mauna Kea's landscape, usually without people in the shot, invoking feelings of remoteness and ecological pureness and, vis-à-vis, the sacredness of Mauna Kea. "Images are, like texts, a key medium used by protesters to communicate a message [...] associated with a complex stock of cultural knowledge and experiences, frames and identifications" [19]. The images of virgin landscape are immediately recognized by residents of the islands as Hawaiian [30] and are aligned with the goals of (some) Kia'i [8] to create a future Mauna Kea without telescopes. When presented side by side, the images used by these accounts reveal the visual ways Kia'i communicate, or their 'visual vernacular' [2]. "By examining the use of images across social media platforms we can attempt to construct a picture of the visual vernaculars which contribute to meaning-making, identity formation and social interaction." [2]. The visual layout of this 'visual vernacular' using Image sorter [28] easily reveals the main themes and aesthetics used by Kia'i. Using Content analysis in this way may shed a light on the meaning making of social movements. However, questions of identity formation and social interaction afforded by producing and distributing these visuals on social media, call for an analysis that goes beyond a temporal or semiotic framework. Following the pivotal research question of Nick Couldry's practice approach to media studies: "What do people do with media"[1], [4] This research asks "what do Kia'i Do with visual social media. To answer this question, the visual methodology of Pearce et al. will be extended to unpack the practices bundled [3] into the practice of using visual social media.

\section{A Practice based Approach to Visual Social Media}

Eder \& Klonk [31] examine how, in recent decades, digital video has become ubiquitous to the extent that it has fundamentally changed practices of political protest, activism, and social movements. Askanius [3] notes how video practices such as documenting, bearing witness or mobilizing, overlap and interact with other activist media practices such as networking and organizing, or building trust, identity, and solidarity. Askanius proposes a practice-based framework as a means of bringing a non-media-centric perspective into the analysis of the role of moving images in social movement politics. By positioning video activism in relation to a range of social and political practices, performed by social movement actors today. Askanius, following Stephansen [32], suggests unpacking activist video practices into a "range of practices that form a bundle of overlapping practices around which video activism evolve" [3]. Following Couldry, Askanius sees activist video practices as an 'anchor practice' [1]. In other words, doing video activism anchors - or 'packs' - within itself other activist media practices, such as: Creating solidarity [19] mobilization [18], bearing witness [33] and identity building [2] . An example for an array of 
practices anchored to activist video practices is illustrated in figure 3 below.

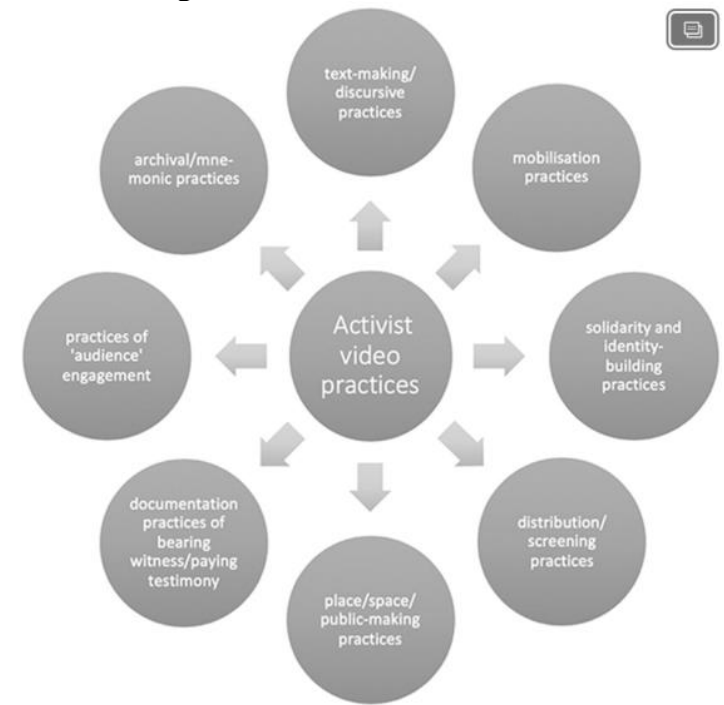

Figure 3. Askanius' 'Bundled practices of video activism' [3]

Visual social media, distributed from smartphones and other networked cameras, has stepped in to replace the role of video recording devices [34] in social activism. The practices of visual social media operate in the same ways as activist video-practices but are amplified by their ability to transmit immediately worldwide with greater efficiency. In what follows, $\mathrm{Pu}$ 'uhonua o $\mathrm{Pu}$ 'uhuluhulu and Protect Mauna a Wākea Instagram accounts will be re-examined, using the image sorter software [28], to unbundle the different practices of social movements anchored to activist Instagram use. Building on Pearce et al.'s methodology, image plotting will be used to exemplify how practice presents itself in the visual vernacular of Kia'i. To achieve this, four practices from the practices presented by Askanius as bundled to activist video, will be unbundled and inspected: Mobilization, identity building, solidarity and bearing witness. These practices were chosen after preliminary manual observation reveled they are the most prominent in these accounts. This analysis will demonstrate how using a practice based lens in conjunction with Visual Cross Platform Analysis [2] may support large scale, non-media-centric analysis of what social activists do with visual social media platforms.

\subsection{Instagram use by Kia'i, a practice based visual analysis}

To present how social movement practice is intertwined into the visual vernacular of Kia'i, the images downloaded from both Instagram accounts were categorized according to the practices identified in them. In total 1,422 images were identified as doing one or more of the four practices chosen for analysis. The process followed Pearce et al.'s suggestion for 'meso-analysis': Creating large image plots and then, reviewing images for finer details [2]. The downloaded images were reviewed manually and sorted into the four practices of social activism outlined above, according to the following criteria:

Practices of Solidarity: Images selected were either showing solidarity, soliciting solidarity, or creating a conversation about solidarity. Images identified as doing solidarity included persons showing support to Kia'i using signs, apparel, and the Ku Kia'i Mauna hand signal $^{1}$. Other images recognized as doing solidarity contained concerts, on and off the Mauna, celebrities visiting the Mauna, other indigenous groups visiting the Mauna, and solidarity campaigns such as celebrities writing 'we are Mauna Kea' on their hands and taking a selfie. In total 266 images, about 18.65\%, were categorized as showing solidarity.

Bearing witness - At first, only images of confrontation with police were collected. Upon review, and bearing in mind Askanius equation of 'bearing witness' with 'documenting'[3], the criterion for the practice of 'bearing witness' evolved to represent witnessing the entire effort of protecting Mauna Kea. Therefore, images of any activity on Mauna Kea, that are clearly not a staged photo for the purpose of solidarity or identity building, were collected. These include processes of constructing tents, demonstrations on the Mauna and in other places, clashes with police, images of arrests, and images of court proceedings. In total 358 images, $25 \%$, were categorized as bearing witness.

Mobilization - In images identified as doing mobilization, the main vernacular which presented itself is written language. Images selected contained written messages, either designed for Instagram or photographs of physical signs. While some contained direct calls to actions: being at a certain place or doing an activity. Other images identified as doing mobilization contained slogans, talking points and inspirational photographs which may inspire viewers into taking action. As mentioned above, this textual use of Instagram is uncharacteristic for the platform, as practice seems to overcome aesthetic conventions. In total 600 images, 42\%, were categorized as doing mobilization.

Identity building -Images selected reflect Hawaiian genealogy in the islands, Hawaiian traditional clothing, Leis, and Hula. As well as Images of Mauna Kea itself,

\footnotetext{
${ }^{1}$ Holding hands together in triangle shape symbolizing the shape of the Mauna as well as genealogy.
} 
Images of Hawaiian flags, Hawaiian Kingdom flags and flags with the symbol of the Mauna. Also included were Images of Hawaiian monarchs as well as leaders of Kia'i Mauna Kea and previous social movements in Hawaii. In total 236 images, 16.5 of images were categorized as identity building.

By applying a practice-based approach Pearce et al.'s methodology can be expanded beyond recognizing visual vernacular, into an understanding of what activists are doing with Instagram. The two accounts examined contribute to "creating a nation" [10] by doing solidarity and identity building, but, as accounts of a living protest, Kia'i mostly use practices of immediate actions. The data collected shows that the most common visual practice for these accounts is mobilization (42\%), followed by bearing witness (25\%). Nevertheless, Nicolini [35], cited by Askanius [3], reminds us that while for analytical purposes practices can be isolated for examination. Empirically, we always encounter multiplicities or arrays of practices. Thus, some of the images appear in two or more categories. There is no mobilization without identity building and no solidarity without bearing witness. To better grasp this 'bundled' aspect of practice, it is again useful to invoke Pearce et al.'s methodology. The following image, produced in image sorter software shows the images identified as one of the four practices analyzed above arranged side by side by practice, in a way that demonstrates how some images appear in more than one practice:

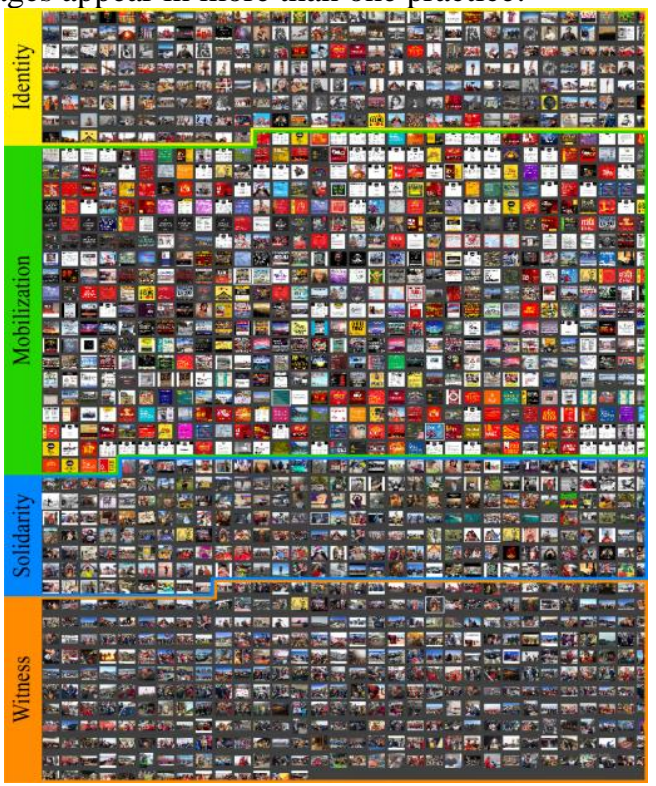

Figure 4. Identified practices. image plot sorted by name in Image Sorter [25]. 1,422 photos.

Segmentation design Marina Karabelnik

This plot allows us to easily view social movement practices as they are bundled into Instagram use practices. Clearly laying out the volume of each practice in the overall visual vernacular. This plot moves away from the content-based analysis suggested by Pearce et al., shifting focus from color and time of posting to what Kia'i are doing with visual social media. Nevertheless, this plot still allows for easy content analysis which could be combined with a practice-based approach to provide deeper level analysis of individual images of interest [15]. Furthermore, this practice-based approach can be juxtaposed with the time of posting to provide understandings of how practices are used before and after major events in the lifecycle of social movements. To exemplify this, the four practices identified in both Instagram accounts are juxtaposed below with the five days leading up to, and following the arrests of Kupuna (Elders) on July $17^{\text {th }}, 2019$ as shown in the table 1

\begin{tabular}{|l|c|c|}
\hline & Overall images & $07 / 13-23 / 2019$ \\
\hline Total identified & 1,422 & 48 \\
\hline Solidarity & $\begin{array}{c}266 \\
(18.65 \%)\end{array}$ & $3(6.25 \%)$ \\
\hline Bearing witness & $358(25 \%)$ & $24(50 \%)$ \\
\hline Mobilization & $600(42 \%)$ & $18(37.5)$ \\
\hline Identity Building & $\begin{array}{c}236 \\
(16.5 \%)\end{array}$ & $3(6.25 \%)$ \\
\hline
\end{tabular}

Table 1. Solidarity, Bearing Witness,

\section{Mobilization, and Identity Building. Overall images compared to the five days before and after the arrests of Kupuna}

By applying a practice-based lens it is easy to see that while overall trends hold, Kia'i employed different practices during the days leading up to the arrests and immediately following them. Days that also included the creation of the blockade on the road leading to the summit of Mauna Kea and the erection of the kupuna tent and of the $\mathrm{Pu}$ 'uhonua o $\mathrm{Pu}$ 'uhuluhulu (The refuge at $\mathrm{Pu}$ 'uhuluhulu). During these days, the main practice of Kia'i on Instagram was bearing witness at $50 \%$, followed closely by mobilization at $37.5 \%$, together taking up $87.5 \%$ of total images, with Solidarity and Identity building practices dwindling during this time of action. By implementing a practice based approach to visual methodology, the practices of visual social media have been unpacked above to provide a nonmedia-centric view that goes beyond the affordances and limitations of the platform, as well as beyond content analysis, to revel what Kia'i do on Instagram to tell their own mo'olelo. 
representational power and those without such access" [4]

\section{Limitations of the study}

The proposed study focused, the site of the image [36]: a platform, where images are seen by the audience. Rose [36] emphasizes the importance of also understanding the socio-economic conditions of image producers, while Hand [15], Askanius [3] and Nicolini [35] remind us that a comprehensive practice based approach must employ ethnographic methods, visiting the sites of image production [36] and interviewing the producers. Therefore, a more complete research will follow Hand's suggestion to accompany visual social media analysis with ethnographic participant observation in the site of the image production and small-scale interviews with the image producers and their audience.

\section{Conclusion}

Kumu Noelle Kahanu, in interview to Oriana Leao asked "what it would take to have just one film, just one community, or just one director that changes the landscape both internally concerning how we identify ourselves and externally in how we manifest agency?" [37]. This work attempts to show how the use of social visual media by Kia'i, as a community, contributes to the representation of Kanaka identity and to the Kanaka mo'olelo of Mauna kea. This work aims to exemplify how visual social media have contributed to overtaking some symbolic capital from state and media institutions, allowing more power to kanaka voices of dissent in the discourse of Mauna Kea and Hawaiian Sovereignty. As shown above, the visual practices of Kia'i Mauna Kea have taken the discourse surrounding Mauna Kea "out of the courts - out of the domain of state authority - [and] constituted a re-territorialization of the political [...] not possible in the sanctioned spaces of the official State hearing [...] or the public meeting, where a strict adherence to a delimited set of criteria under question is required, while all other factors are, by necessity, expelled from consideration." [9]. This article expands the focus on visual social media in the study of social movements as well as on a practice-based understanding of social movements and visual media. Lastly, this article serves as a case study for future examinations of social protest. offering tools to expand the understanding of how practices of visual social media contribute to the reclaiming of social capital back from state and media, to the public. Diminishing "The division of the social between those with access to media's vast concentrations of

\section{References}

[1] N. Couldry, "Theorising media as practice," Soc. Semiot., vol. 14, no. 2, pp. 115-132, 2004.

[2] W. Pearce et al., "Visual cross-platform analysis: digital methods to research social media images," Inf. Commun. Soc., vol. 0, no. 0, pp. 1-20, 2018.

[3] T. Askanius, "Video activism as technology, text, testimony-or practices?," in Citizen Media and Practice. Currents, Connections, Challenges, H. C. Stephansen and E. Treré, Eds. Taylor \& Francis, 2019.

[4] N. Couldry, Media, Society, World. Social Theory and Digital Media Practice. 2012.

[5] M. A. Brown, "Mauna Kea: Ho'Omana Hawai'i and protecting the sacred," J. Study Relig. Nat. Cult., vol. 10, no. 2, pp. 150-169, 2016.

[6] E. Case, "I ka Piko, To the Summit: Resistance from the Mountain to the Sea," J. Pac. Hist., vol. 54, no. 2, pp. 166-181, 2019.

[7] J. Osorio, "Mo'olelo and Governance: How Kapu and Kānāwai are overthrowing Law and Order in the Settler State of Hawai'i The," 2020.

[8] J. E. Ciotti, "Historical Views on Mauna Kea: From the Vantage Points of Hawaiian Culture and Astronomical Research.," Hawaii. J. Hist., vol. 45, pp. 147-166, 2011.

[9] J. A. Salazr, "Multicultural Settler Colonialism and Indigenous Struggle in Hawai ' I : the Politics of Astronomy on Mauna a W Ā Kea a Dissertation Submitted To the Graduate Division of the University of Hawai ' I At M A Noa in Partial Fulfillment of the Requirements Fo," University of Hawai'i at Manona, 2014.

[10] J. Keane-Lee, Standing Above the Clouds. PIC, 2019.

[11] Z. Tufekci, Zeynep Tufekci Twitter and Tear Gas . The Power and Fragility of Networked Protest. 2017.

[12] J. Adams, "Art in Social Movements: Shantytown Women's Protest in Pinochet's Chile," Sociol. Forum, vol. 17, no. 1, pp. 21-56, 2002.

[13] N. K. Silva, "Multicultural Setller Colonialism and Indigenous Struggle In Hawai'i : The Politics Of Astronomy On Mauna A W Ā Kea," 2014.

[14] A. L. P. Lum, "Navigating Our Past, Pesent, and Future Using Mo'olelo: Sitting Beside Our Ancestors," UNIVERSITY OF HAWAI'I AT MĀNOA, 2017.

[15] M. Hand, "Visuality in Social Media: researching images, circulations and practices Martin Hand, Queen's University, Canada. Draft for publication in Sloan, L. Quan-Haase, A. (eds.) (2017) The Sage Handbook of Social Media Research Methods , London: Sage.," pp. 1-38, 2017.

[16] S. Sontag, On photography, vol. 48. Macmillan, 2001. 
[17] T. Highfield and T. Leaver, "Instagrammatics and digital methods: studying visual social media, from selfies and GIFs to memes and emoji," Commun. Res. Pract., vol. 2, no. 1, pp. 47-62, 2016.

[18] N. Doerr, A. Mattoni, and S. Teune, "Toward a visual analysis of social movements, conflict, and political mobilization," Res. Soc. Movements, Conflicts Chang., vol. 35, no. December 2018, 2013.

[19] Paul M. Muchinsky, “済無No Title No Title,” Psychol. Appl. to Work An Introd. to Ind. Organ. Psychol. Tenth Ed. Paul, vol. 53, no. 9, pp. 16891699, 2012.

[20] "Protect Mauna a Wākea Instagram account." [Online]. Available:

https://www.instagram.com/protectmaunakea/?hl=e n. [Accessed: 06-May-2020].

[21] M. Shavonn and R. Chelsea, "Mauna Kea research guide," University of Hawai'i, Maui., 2019.

[Online]. Available:

https://maui.hawaii.libguides.com/c.php?g=962049

$\& \mathrm{p}=6947938$. [Accessed: 08-Jul-2020].

[22] "Kanaeokana Instagram account." [Online]. Available:

https://www.instagram.com/kanaeokana/?hl=en. [Accessed: 08-Jul-2020].

[23] "Kāko'o Haleakalā Instagram account."

[24] "Pu'uhonua o Pu'uhuluhulu Instagram account." [Online]. Available: https://www.instagram.com/puuhuluhulu/?hl=en.

[25] “Kāko’o Haleakalā Facebook page.” [Online]. Available: https://www.facebook.com/watch/kakoohaleakala. [Accessed: 08-Jul-2020].

[26] "Pu'uhonua o Pu'uhuluhulu Website," 2019. [Online]. Available: https://www.puuhuluhulu.com/. [Accessed: 08-Jul-2020].

[27] "Downloader for Instagram ${ }^{\mathrm{TM}}+$ Direct Message." aboveradiant@gmail.com, 2020.

[28] V. Computing, "Image Sorter." HTW Berlin, Berlin, 2018.

[29] K. Lobinger, "Photographs as things - photographs of things. A texto-material perspective on photosharing practices," Inf. Commun. Soc., vol. 19, no. 4, pp. 475-488, 2016.

[30] A. Meredith and A. Committee, "Imaging and Imaginings of Hawaiianness in the Contemporary," University of Alaska, 2010.

[31] J. Eder and C. Klonk, Image operations: Visual media and political conflict. Manchester University Press, 2016.

[32] H. Stephansen, "Understanding citizen media as practice: agents, processes, publics," Citiz. Media Public Spaces Divers. expressions Citizsh. dissent, pp. 25-41, 2016.

[33] K. Andén-Papadopoulos, "Citizen camerawitnessing: Embodied political dissent in the age of 'mediated mass self-communication,"' New Media Soc., vol. 16, no. 5, pp. 753-769, 2014.

[34] A. Tifentale, "Art of the Masses : From Kodak Brownie to Instagram," Netw. Knowl., vol. 8, no. November, pp. 1-16, 2015.

[35] D. Nicolini, "Practice theory as a package of theory, method and vocabulary: affordances and limitations," in Methodological reflections on practice oriented theories, Springer, 2017, pp. 1934.

[36] G. Rose, Visual methodologies: An introduction to researching with visual materials. sage, 2016.

[37] O. Leao, "Miss Represented: Misrepresentations of Kānaka Maoli Women in American Cinema and Mo'olelo as Alternative Method," University of Hawai'i at Mānoa, 2016. 